\title{
Interactive Software to Design and Diagnosis Pumping Systems for Engineering Professionals
}

\author{
Andrés Escorcia Varela, Guillermo Valencia Ochoa, Marley Vanegas Chamorro \\ Grupo de investigación en Gestión Eficiente de la Energía - Kaí, Faculty of Engineering \\ Universidad Del Atlántico, km 7 antigua vía Puerto, 081008, Barranquilla, Colombia. \\ *gescorciaingmecanica@gmail.com, guillermoevalencia@mail.uniatlantico.edu.co, \\ marleyvanegas@mail.uniatlantico.edu.co
}

\begin{abstract}
Nowadays, the engineers dealing with the pumping systems try to promote the rational use of energy and environmental conservation by mean of good operational practices in the different types of equipment involved. This position is commonly occupied by professionals in electrical, mechanical, electromechanical engineering and other related specialties who do not have in-depth knowledge of pumping systems, and in additions have the objective of complying with the energy budget or implementing saving measures. It is the duty of the energy manager to adhere to the amount of energy stipulated or projected in the production index of the companies, to have this indicator in excellent condition to contribute both the company's economy and the global warming reduce. Therefore, this paper focuses on the use of a pumping systems software that allows engineers and professionals from other branches to acquire the necessary knowledge to evaluate the pumping systems that are in operation in the industry or make new designs based on the energy efficiency approach to meet operational conditions such as the flow rate and the static head required. The informatics application allowed to encourage engineers in the industrial sector to appropriate knowledge of energy consumption behavior with the variables involved in the transport of fluids such as temperature, type of fluid to be transferred, quality of piping, handling of accessories, pump curves, among others. Finally, the software can be used to avoid the operation of pumps far from the point of operation of the current system and to analyze the investment costs, taking into account the periods of activity and installation of the array.
\end{abstract}

Keywords - Efficiency, Pumping Systems, Software, Energy Diagnosis

\section{INTRODUCTION}

The energy efficiency is playing an increasingly important role in the new industrial scenarios in the world. In the area of fluid mechanics and incompressible fluid pumping systems, a high percentage of energy consumption of $22 \%$ of world energy production is present, which imply to pay attention and review from the energy point of view whether energy is being used in the best way. Designing a pumping system requires extensive calculation and knowledge that had been programmed to facilitate their computer [1,2]. In the area of fluids mechanics, the correct manipulation of these computer applications present in the market has presented a fundamental role, because of they are normally used in the design and planning stage to reduce operational and investment cost. Many times if the operating conditions of the systems change, such as the amount of fluid required, and this situation was no considered through a computational tool, the design process could result in an oversized pump, and therefore, the pump will operate in an unsatisfactory condition, reducing the head capacity to be able to supply the requested flow at low efficiency. Either of the two previous cases generates energy losses or process problems by not delivering the necessary head height when not operating at the best efficiency point can be studied with computational applications [3].

In industrial sector companies, pumping systems can be summarized in a global scheme as presented in ISO/ASME 14414 in its document for energy saving in pumping systems, at the top is the marketer who delivers the energy, follow the substation elements to achieve the necessary voltage, surge or high current protection elements, couplings, electric motor, variable speed drive, pump, control valves, piping and accessories and the final delivery point which may be storage tanks, tanks etc. From this result, a comparison point is obtained for the pumping equipment that is working in the plant and the optimal equipment that should be. This is the reason due to some researcher had been developing software that allows energy management professionals perform an inspection or make new designs of pumping systems considering the energy efficiency point of view, making them more competitive regarding price and quality [4].The HYPUMP ENERGY software was developed on the Visual Studio Professional platform, in the C\# programming language, powered by the CoolProp open access library [5], which has the compilation of numerous empirical and theoretical models for the prediction and correlation of the thermophysical properties of pure fluids and mixtures treated as pseudopure fluids, the above allows the selection from a list of 110 fluids and establishes a broad picture for the 
subsequent simulation, helping the engineer to dimension the effect of dynamic and kinematic viscosity, specific weight and temperature on the amount of energy required for the back.

It's easy to find quick applications that tell you how much energy and money you can save by adding a variable speed drive to your system, and that's because it's an efficient way to act on a system that's already designed and installed to improve average efficiency of the pump from $6 \%$ to $9 \%[6]$. However, there are more possibilities to simulate before to select or design the pumping systems for savings, such as heating the fluid, cutting the pump impeller, the selection of the correct diameter compared to the nominal speed at which the system will work, remember that the primary and secondary losses increase at the square of the speed $[7,8]$.

For this reason, the main contribution of this paper is to presents an interactive software to design and diagnose pumping systems with the energy efficient management criteria. A case study analysis is presented with the assistant of the software evaluating all the possibilities of saving, the effect of changing some parameter and operation condition such as sudden widening to a gradual one $[9,10]$, the system temperature, the influence of NPSH, among other parameters.

\section{PRESENTATION OF THE SOFTWARE}

The HYPUMP ENERGY software was focused to develop the critical thinking of engineering student or professional in term of the energy management criteria, and the correct selection of the components of a pumping system based on the energy efficiency since they contribute to the global warming with more than 79 Mton $\mathrm{CO}_{2}[11]$. In addition, the software is conceived with the concept of the energy efficiency triangle [12], where the good relation between the purchase, maintenance, and energy efficiency of the systems allow for optimal management in the companies. Through case studies developed with the software, the engineer can determine the critical components of the system that have the most significant impact on energy consumption according to the conditions on site and the working fluid.There are a lot of software and applications available on the web for the design and simulation of pumping systems, but they end up being very complicated and require more time to be handled correctly by the user, among these we find ASPEN Plus with a long history in the field of simulation in stationary mode and dynamic mode [13], but expensive license, HIDROFLO 3.0, PUMP-FLO, PC-PUMP which offer standard calculations, the comparison between pumps, between additional equipment, and between different operating conditions which gives the designer a broader picture, some very complete indeed, but with a cost that not all are available to pay.

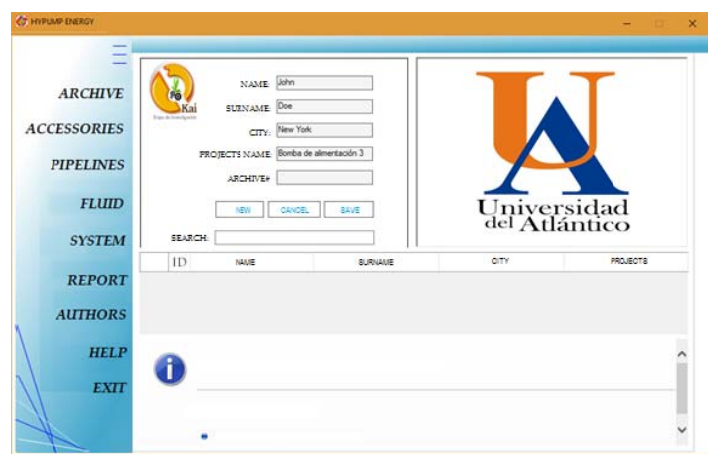

a)

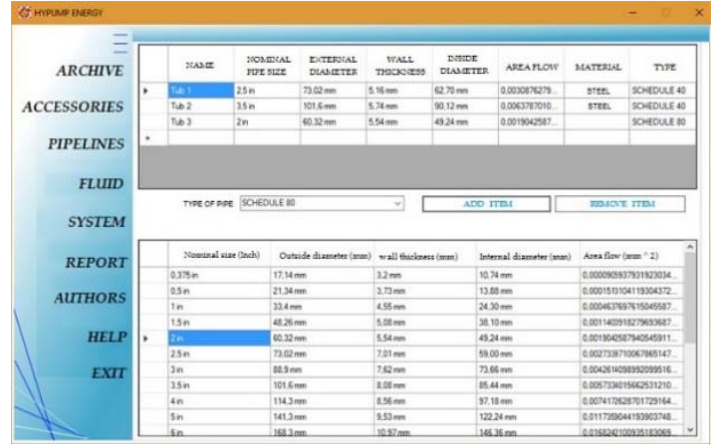

c)

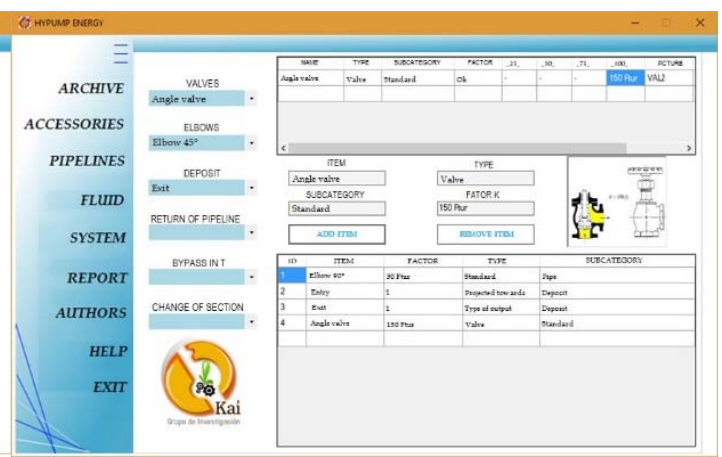

b)

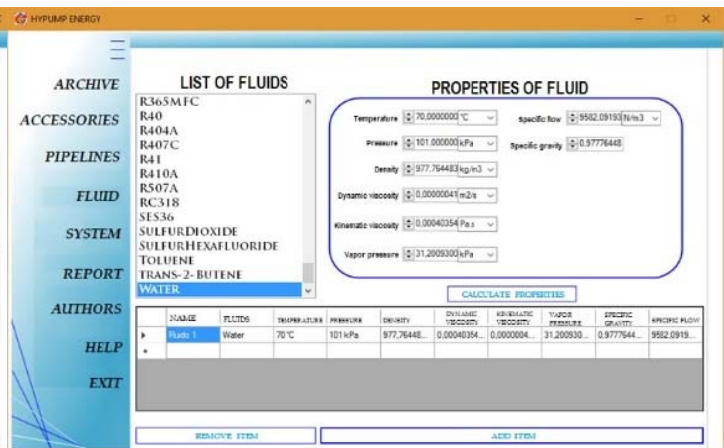

d)

Fig.1. Main Hypump Energy windows, a) register and save projects; b) selection of fittings; c) selection of pipes; d) selection and definition of parameters of the fluids to be processed 
In Fig. 1, you can see the initial screen of the software, where the user can enter user data and some identification fields for the pumping system, as next window we find the accessories that the user can add to work on the design of the pumping system taking into account the $\mathrm{K}$ factor and availability of opening if it is a valve, the next window is for the selection of pipe, where the user can find an extensive library of different Schedule types and materials, followed by the fluid window where the user must define the temperature and pressure parameters to calculate the rest of the properties of the fluid selected from an extensive list powered by the Coolprop Fluid Library, an advantage is the flexibility of the units, as the user can switch between the metric and the English system. After having defined all the above elements, the system window allows you to start setting the entire system and requires the user to enter flow, pipe velocities if known, suction pressure and discharge pressure.

Fig. 2 shows the system window, where the necessary pipe sections, their roughness, and length are added and configured in an intuitive and didactic way, and the quantity and location of the fittings in the part of the accessories. If the user places a gradual expansion and the diameter of the pipe at the expansion inlet is higher than the width of the expansion outlet pipe, the software will detect the error and inform the user that he must adjust the inlet pipe to a smaller diameter than the outlet diameter.

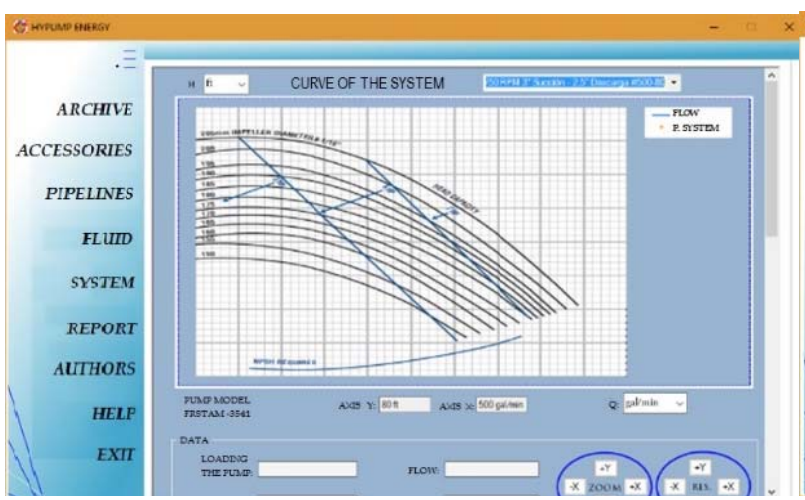

$2 \mathrm{~A}$

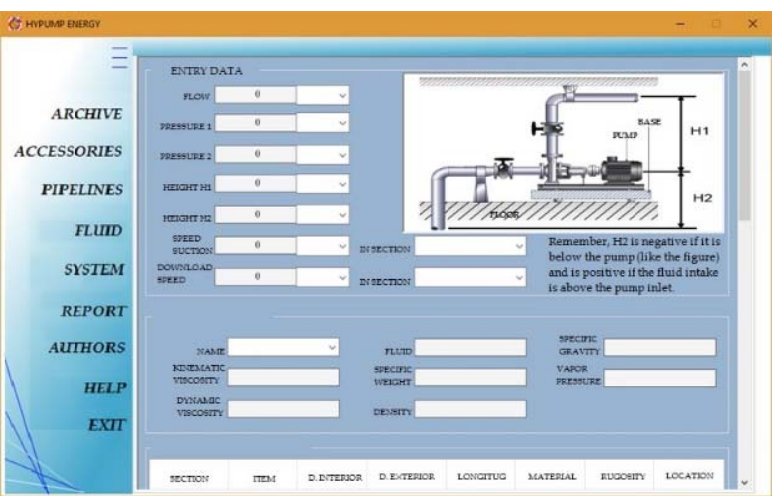

2B

Fig. 2.A is the system window and B the system report window, Hypump Energy

The energy efficiency and the choice of the elements that make up the pumping system go hand in hand to respond to the final design, a high installation cost for choosing a large diameter pipe seems to be a mistake and generates that they decide to reduce the diameter until they reach lower prices, but this leads to paying excessive amounts of money in energy consumption due to ignorance of the factors that really alter the consumption. To avoid these situations, a section was added to the energy cost analysis software to help designers find optimal diameters and the correct selection of pumps regarding efficiency. In Fig. 3 we can see that the user can enter in this section the operation time, interest, estimated work, years of operation of the system.

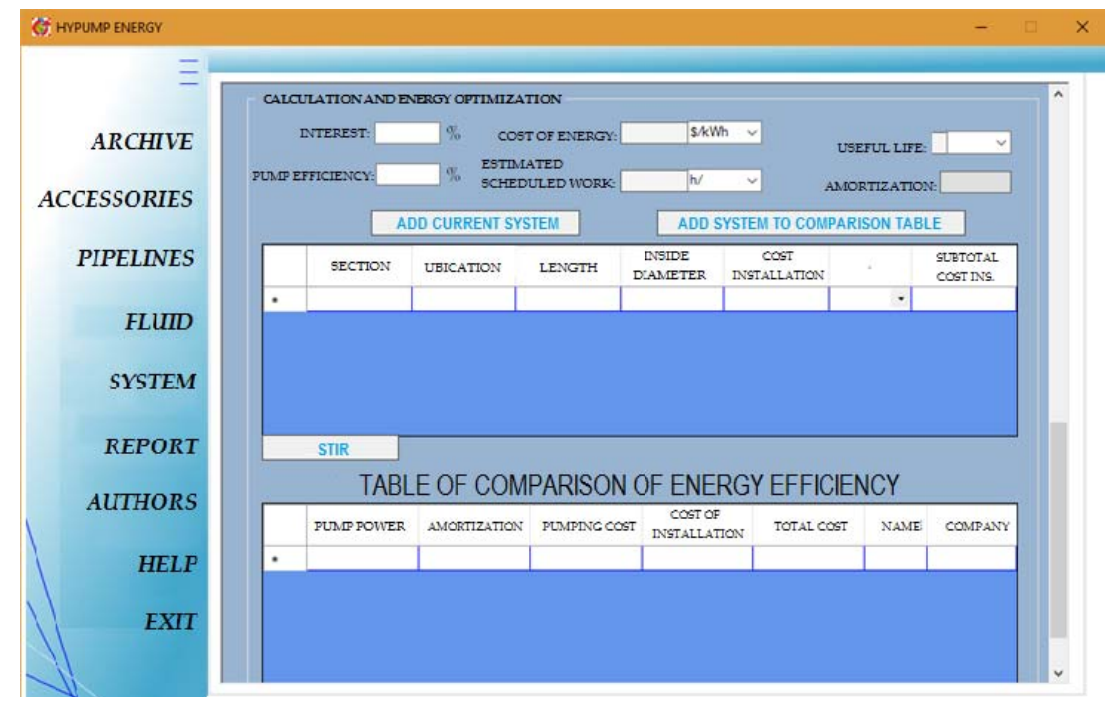

Fig. 3.Energy efficiency and cost analysis window 
The current situation of energy management in the Colombian company in the purchase of equipment focuses on reducing the initial investment cost and installation times, instead of evaluating the life cycle costs using new efficient technologies and including efficiency and energy management criteria in new designs. In pumping systems, the issue has evolved over the last 15 years due to the union of European and American institutions. [14], which shows the concept of the LCC (Life cycle cost) developed by Enersave and complemented with other methodologies for the advice of pumping systems in search of savings and improvements from the current conditions. Equation (1) shows the components of the life cycle cost of a pumping system, which in our case is limited to working only with the Cycle, Cin, Ce; it is assumed that the other costs are the same for the designs presented in the case study:

$L C C=\left(C_{i c}+C_{i n}+C_{e}+C_{o}+C_{m}+C_{s}+C_{a m b}+C_{d}\right),(1)$

$C_{i c}$ is the initial cost, purchase cost (pump, system, piping, fittings). $C_{i n}$ is the installation and commissioning, $C_{e}$ the power costs, $C_{o}$ is operation cost (cost of normal system monitoring work), $C_{m}$ the maintenance cost (parts, labor hours), $C_{s}$ is the breakdown time (production loss), $C_{a m b}$ correspond to the environmental costs and $C_{d}$ th withdrawal/definitive closure.

\section{FLOWCHART AND EQUATIONS}

The software flow diagram can be seen in Fig. 4, the process of designing a pumping system from the first step which is to determine the distribution of the piping networks and define the maximum allowable operating pressure (MAOP), in this part, the designer must make decisions regarding the maintenance and operation of the system. Therefore he must foresee as much as possible the current and future needs that may arise. The second and most important element is the fluid to be transferred, as it defines the type of pipe and its roughness. The kind of pump must be properly selected to ensure low running costs over the lifetime of the pumping system which is approximately $85 \%$. The above criteria affect the energy efficiency of the system. Therefore, the final section of the software allows the user to identify and modify the parameters called significant energy performance variables that are independent of operation and maintenance, operation-dependent variables and static variables (pipe losses). 


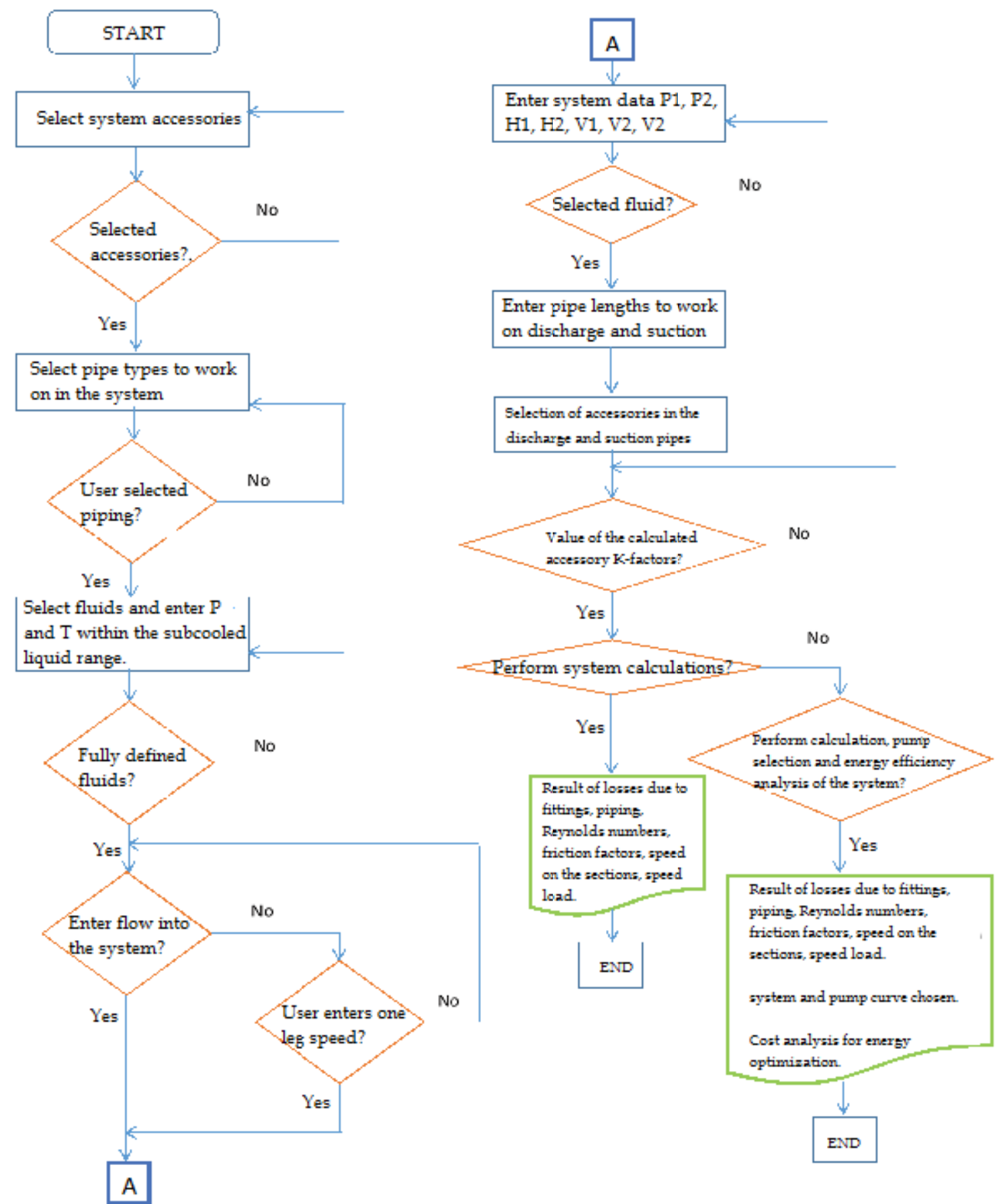

Fig. 4. HYPUMP ENERGY V1.0 software flowchart

HYPUMP ENERGY is based on the fundamental equations of fluid mechanics obtained by the application of the conservation of thermodynamics and mechanics to a fluid volume, studied by Newton, Navier, Stokes, Reynolds, Bernoulli, Darcy and many others skilled in this field of physics, where the equations of continuity, quantity of movement and conservation of energy are developed, necessary for the prediction of energy $[15,16]$. Newton's law of viscosity for Newtonian fluids that have constant viscosity is expressed as seen in the following equations (2) through (4):

Dynamic viscosity equation (Newton's Law),

$\tau=\mu \mathrm{dv} / \mathrm{dy}(2)$

$\mu=\mathrm{dy} / \mathrm{dv} \tau(3)$

Kinematic viscosity equation,

$\mathrm{V}=\mu / \rho(4)$ 
Another important principle is that of continuity since nothing is stored in the transport of a fluid, what goes in must come out as we see in equation (5). And finally, the Bernoulli principle which expresses the conservation of energy written in the form of a theorem by the mathematician Daniel Bernoulli in 1738, which we observe in equation (6).

Equation of continuity,

$v_{1} d_{1}^{2}=v_{2} d_{2}^{2}(5)$

Bernoulli's equation,

$z_{1}+\frac{v_{1}^{2}}{2 g}+\frac{P_{1}}{\gamma}+h_{A}-h_{R}-h_{L}=z_{2}+\frac{v_{2}^{2}}{2 g}+\frac{P_{2}}{\gamma}(6)$

The total energy losses $h_{L}$ are given by equation (7)

$h_{L}=\sum$ Lossesonaccessories $+\sum$ Frictionlossesinpipins $(7)$

where,

$h_{s}=K_{s}\left[\frac{v^{2}}{2 g}\right]$, are the accessory losses

$h_{l}=f \frac{L}{D}\left[\frac{v^{2}}{2 g}\right]$,are the linear losses (9)

where, $f$ is the friction coefficient, L correspond to the length of pipe, D is the pipe diameter and $K_{S}$ the loss coefficient singular.

Three types or zones are defined according to the kind of fluid flow: the first is the laminar flow zone, the second is an intermediate or so-called transition zone, and the third is the turbulence zone where there is a more significant disorder. The Irish engineer Osborn Reynolds experimentally defined the Reynolds number as the ratio of viscous and inertia forces, for circular pipes, the intervals from 0 to the critical Reynolds 2000 or 2100 number are handled according to different authors, it is the laminar flow zone, from 2100 to 4000 it is the transition zone of laminar-turbulent flow, and from 4000 onwards it is the turbulent flow zone.Reynolds' number is given in equation (10)

$N_{R}=\frac{\gamma v D}{\mu},(10)$

Where, $\gamma$ is the Specific weight of the fluid, $v$ is the characteristic fluid velocity, $D$ is diameter of the pipe through which the fluid flows and $\mu$ correspond to dynamic viscosity of the fluid.

Reynolds' critical number is $N_{R c r}=2000$, it is necessary to define the number of Reynolds because of this and along with the roughness, and internal diameter of the pipe is the friction loss factor which allows finding the losses caused by the friction generated between the movement of the fluid on the walls of the pipe or different accessories, there is an equation for the friction loss factor for laminar flow called the Hagen-Poiseuille law as observed in equation (11) and equation (12)

$\mathrm{hL}=(32 \mu \mathrm{L} v) /\left(\gamma \mathrm{D}^{2}\right)(11)$

$\mathrm{f}=64 / \mathrm{N} * \mathrm{R}$

$\mathrm{hL}=\mathrm{f} \mathrm{L} / \mathrm{D} \mathrm{v}{ }^{2} / 2 \mathrm{~g}(13)$

The terms of the above equation are defined as $\mathrm{h} \_\mathrm{L}$ as the friction loss, $\mathrm{f}$ is the Darcy's friction factor, $\mathrm{L}$ is the length of pipe, $\mathrm{D}$ the pipe diameter, $\mathrm{v}$ is the average fluid velocity, and $\mathrm{g}$ the acceleration of gravity.

The friction loss factor for transition and turbulent flows is calculated using the explicit solution given by researchers Prabhata K. Swamee and Akalank K. Join to the expression of the Colebrook-White formula as observed in EC 14:

$f=\frac{0,25}{\left[\log _{10}\left(\frac{1}{3,7 D / \epsilon}+\frac{5,74}{N_{R e}^{0,9}}\right)\right]^{2}}(14)$

Many other formulas have been developed to improve your approximation by decreasing the relative error by giving an explicit solution to the Colebrook-White equation. But the selected one delivers good results despite having relative errors greater than $2 \%$. 


\section{PRACTICAL GUIDE FOR THE DESIGN OF PUMPING SYSTEMS TAKING INTO ACCOUNT ENERGY EFFICIENCY}

The user must first select according to the supplied diagram the fittings, pipes, and fluid to the provided conditions. We then go to the system tab to enter the installation conditions, tank heights, additional pressures, length and configuration of pipe sections, final shape and quantity of fittings at the suction and discharge stage.

The atmospheric pressure of $101.15 \mathrm{kPa}$ is taken, there is no temperature transfer between the water and the outside, so the temperature is kept constant at $70^{\circ} \mathrm{F}$ throughout the distribution. The system is calculated for the first condition where the discharge pipe is 2" Sch 40, as shown in Fig. 5.

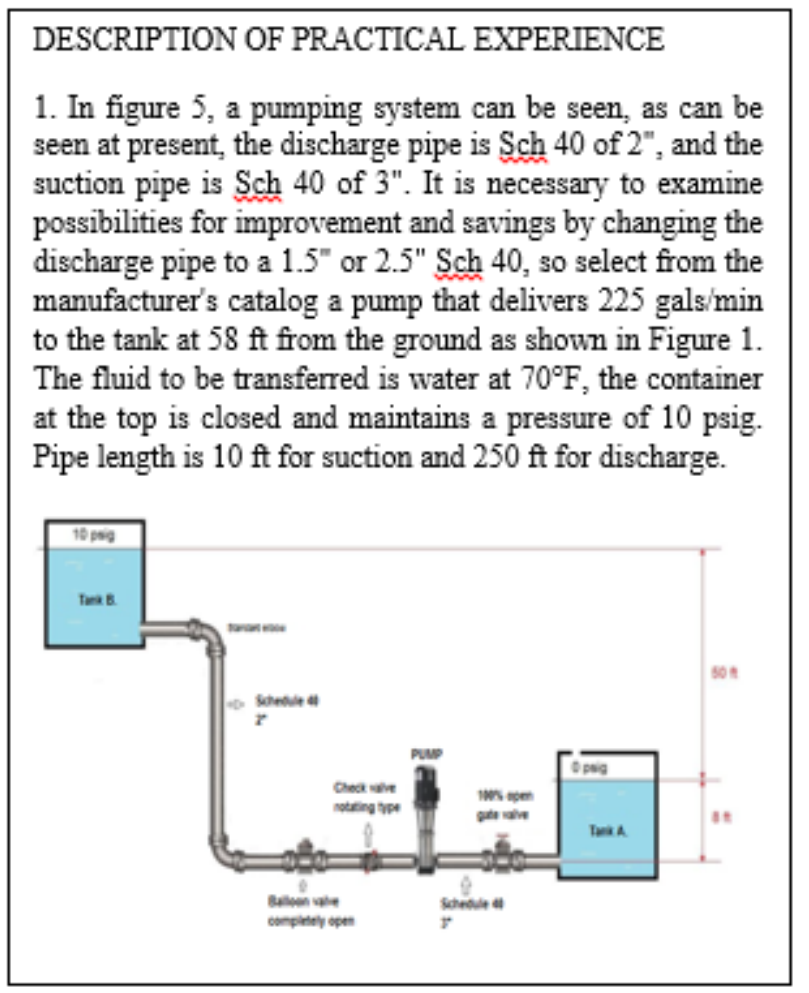

Fig. 5. Pump System, case study of possible improvement

Fig. 6. Case study proposed by HYPUMP ENERGY.

As a first step, we added all the accessories shown in the array, as shown in fig. 7.

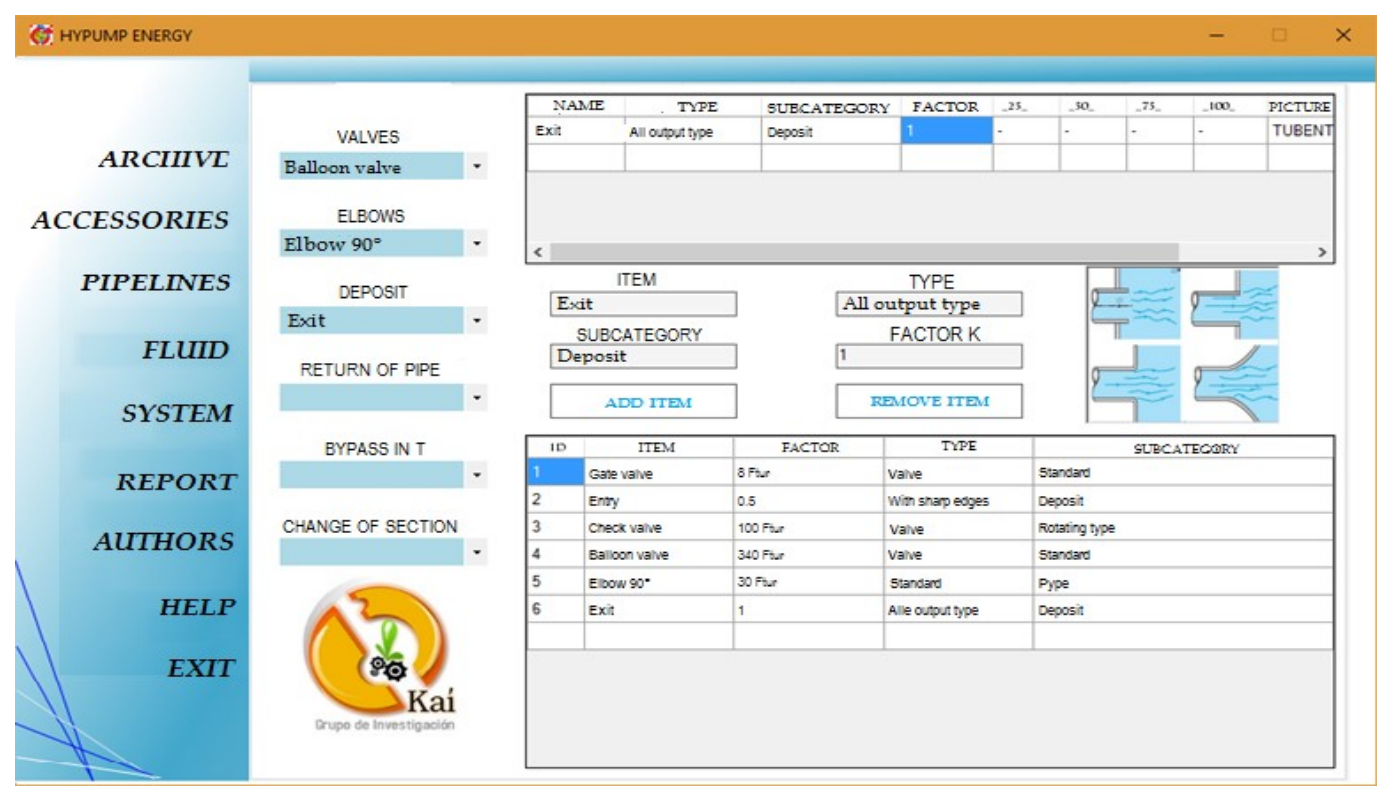

Fig. 7. Case study proposed by HYPUMP ENERGY, selection of accessories 
Let's add the types of pipe to work,

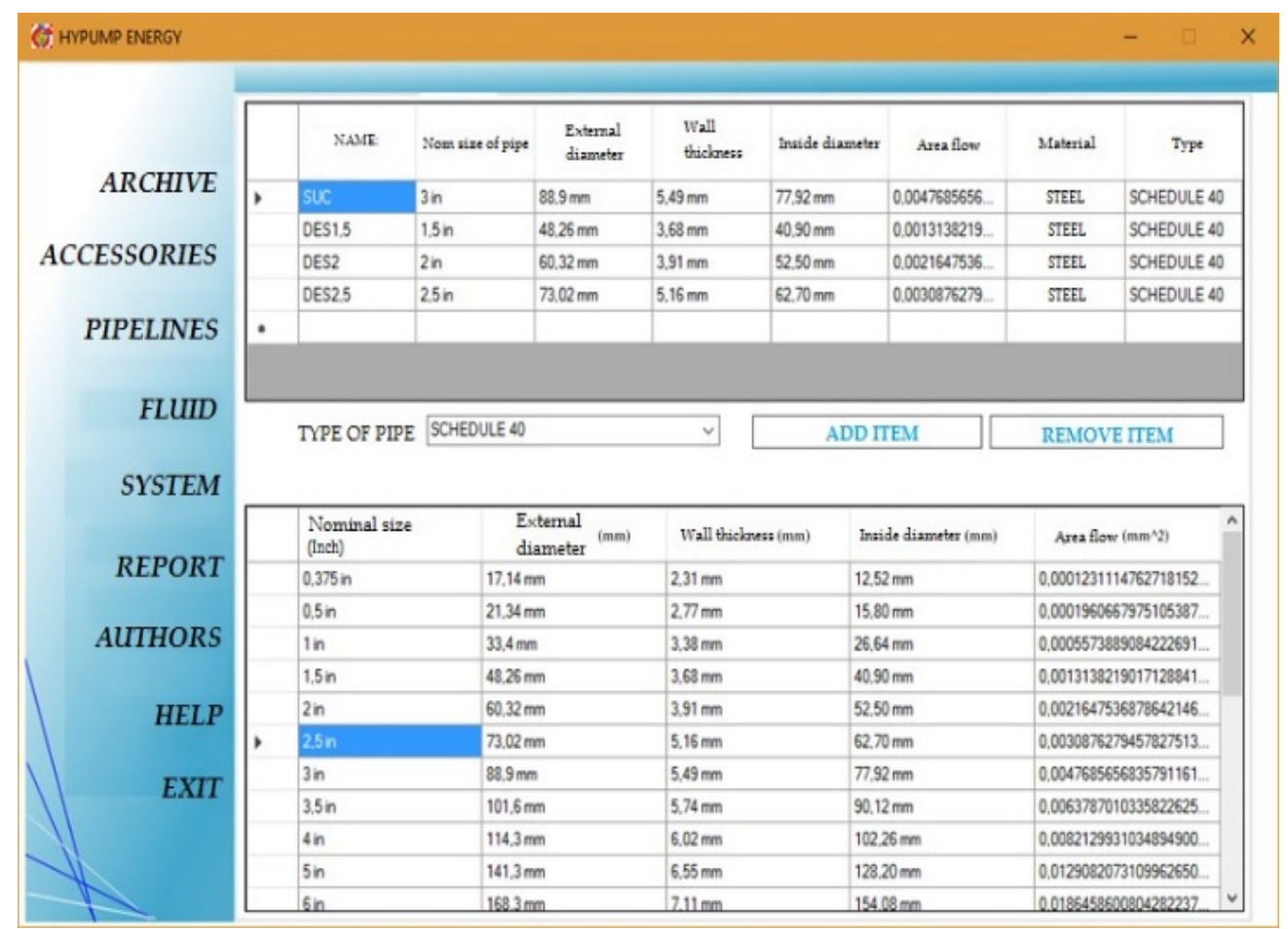

Fig. 8. Case study proposed by HYPUMP ENERGY, pipe selection

We select the fluid according to the conditions requested by the statement, water at $70^{\circ} \mathrm{F}$.

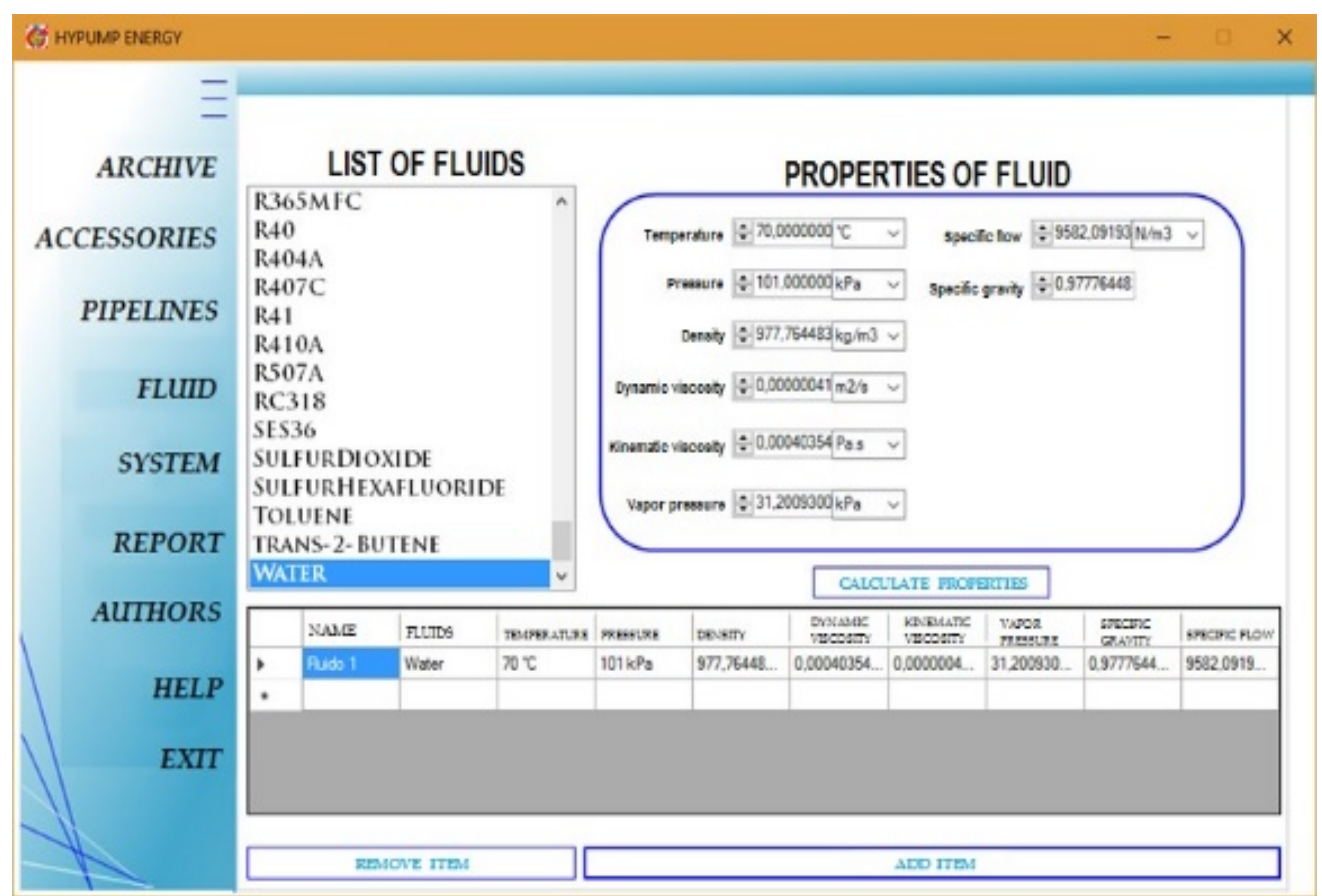

Fig. 9. Case study proposed by HYPUMP ENERGY, fluid selection 
We indicate the array parameters for point one input and two outputs.

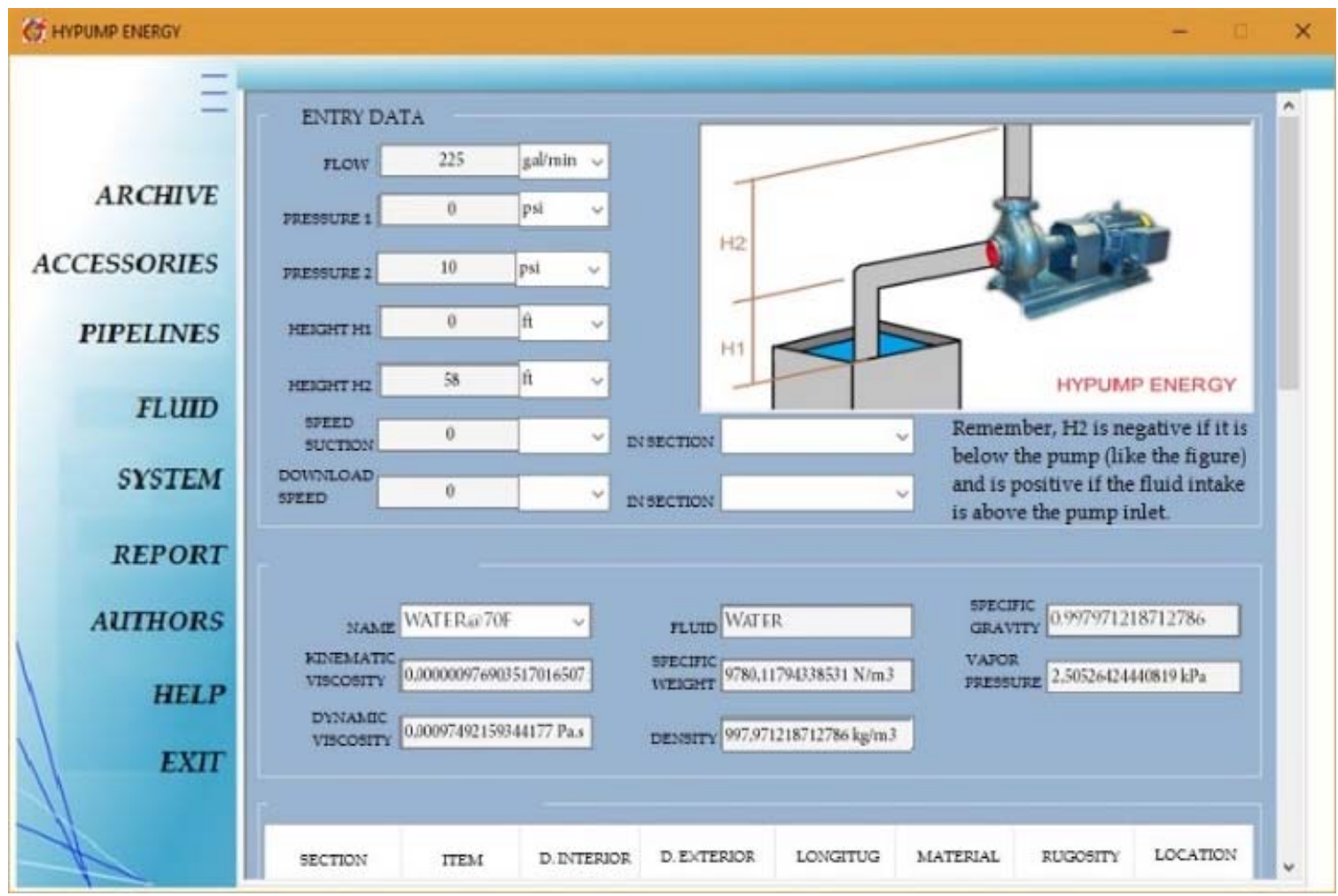

Fig. 10. Case study proposed by HYPUMP ENERGY, schema data

Fig. 11 shows the main values of the system, the energy consumption of the pump at an efficiency of $70 \%$ is $22.03 \mathrm{kWh}$, and the annual cost of its operation is $16,519,785 \$$ year.

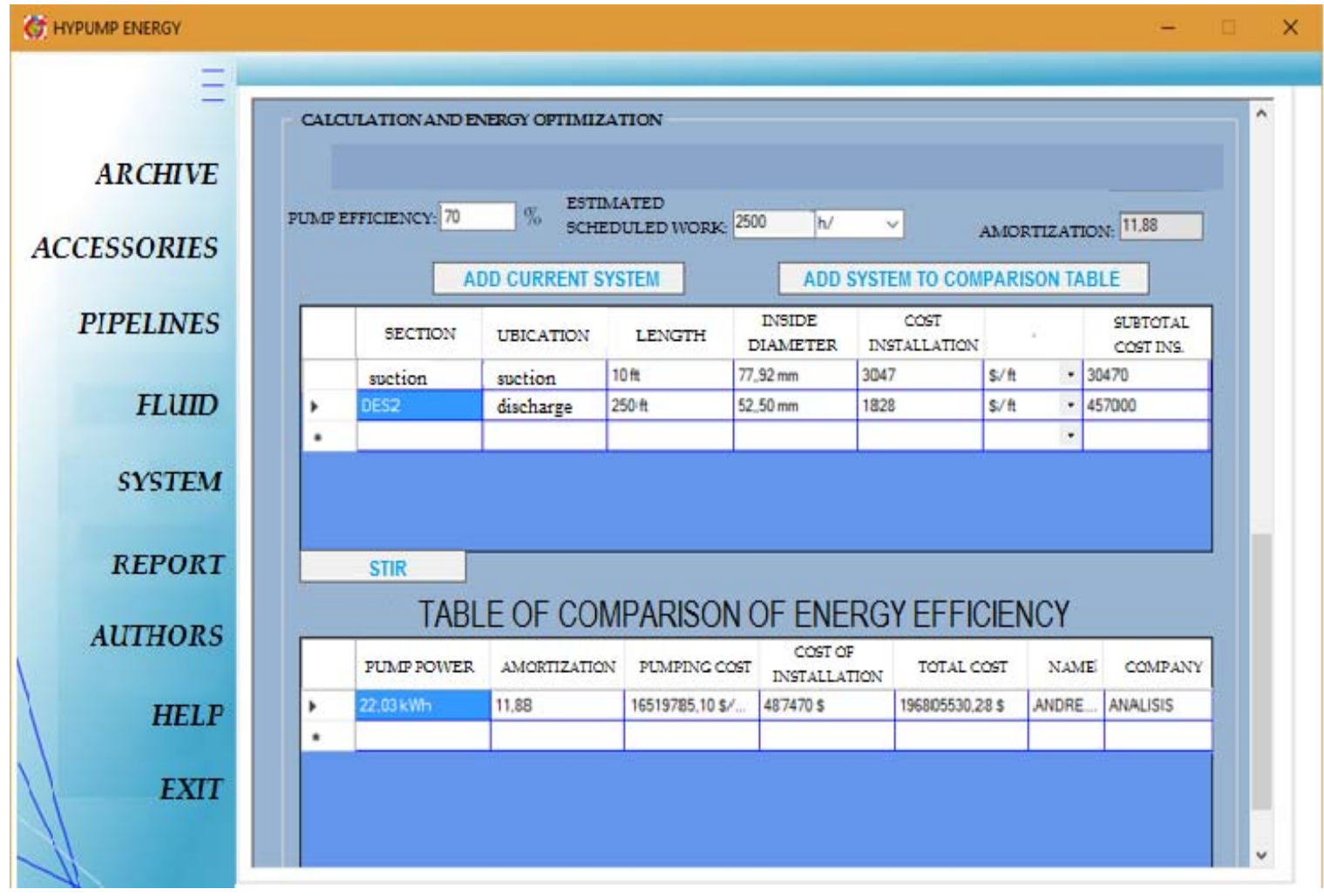

Fig. 11. Comparison table, current system with 2" schedule 40 discharge 
The latter system requires less power to operate the pump and therefore a $55 \%$ lower pumping cost than the current system with a 2" discharge pipe. Demonstrates the influence of a poorly selected diameter because comparing the current diameter versus the proposed diameter of $2.5 "$ Sch 40 results in energy savings of just over half.

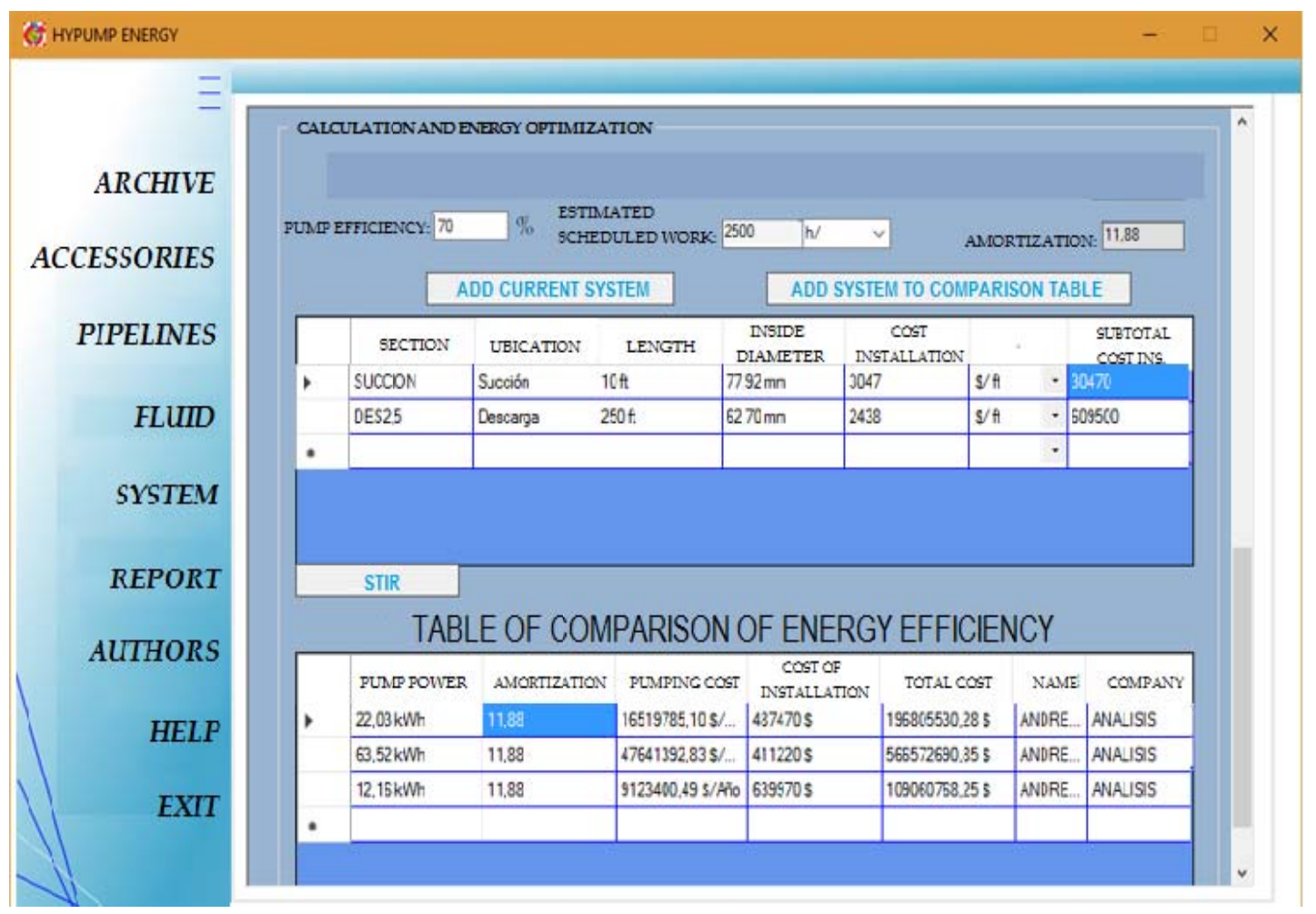

Fig. 12. A comparison table proposed the system with 2.5 " schedule 40 discharge

Another important factor is the Best Efficient Point, which depends on the pump purchased or the design of the entire system. Hypump Energy has some standard pump curves in the market to land the design and face the student or engineer specialist to the use of the pump curves which are directly related to the rpm delivered to the shaft of the same or as a second parameter the diameter of the impeller.

Table 1 shows the values of the installation cost in Colombian pesos per foot and per meter for the different diameters proposed. Both units can be used in the software for comparison to determine installation costs. The values used for the price of installing the pipeline are assumptions close to those used in the construction sector in Colombia, maintaining the logic that the larger the diameter the cost increases.

TABLE I. Proposed case study, system curve vs pump curves

\begin{tabular}{|ll|l|l|l|l|}
\hline \multicolumn{5}{|c|}{ Installation cost for different diameters of pipes } \\
\hline $\mathbf{1 , 5}$ & SCH 40 & $\$ / \mathrm{m}$ & 5000 & $\$ / \mathrm{ft}$ & 1523,99 \\
\hline $\mathbf{2 "}$ & SCH 40 & $\$ / \mathrm{m}$ & 6000 & $\$ / \mathrm{ft}$ & 1828,79 \\
\hline $\mathbf{2 , 5 "}$ & SCH 40 & $\$ / \mathrm{m}$ & 8000 & $\$ / \mathrm{ft}$ & 2438,39 \\
\hline 3" & SCH 40 & $\$ / \mathrm{m}$ & 10000 & $\$ / \mathrm{ft}$ & 3047,99 \\
\hline
\end{tabular}

Fig. 13, shows a selection of a pump that can satisfy the total pump head and the requested flow rate, the yellow dot indicates the operating point in the system curve, we see that the $180 \mathrm{~mm}$ diameter impeller is the closest, and we would have an energy consumption of $20 \mathrm{HP}(14 \mathrm{~kW})$ a little more than that calculated by the program assuming a pump with $70 \%$ efficiency with $12.2 \mathrm{~kW}$, if we select this pump $12.8 \%$ of the energy. 


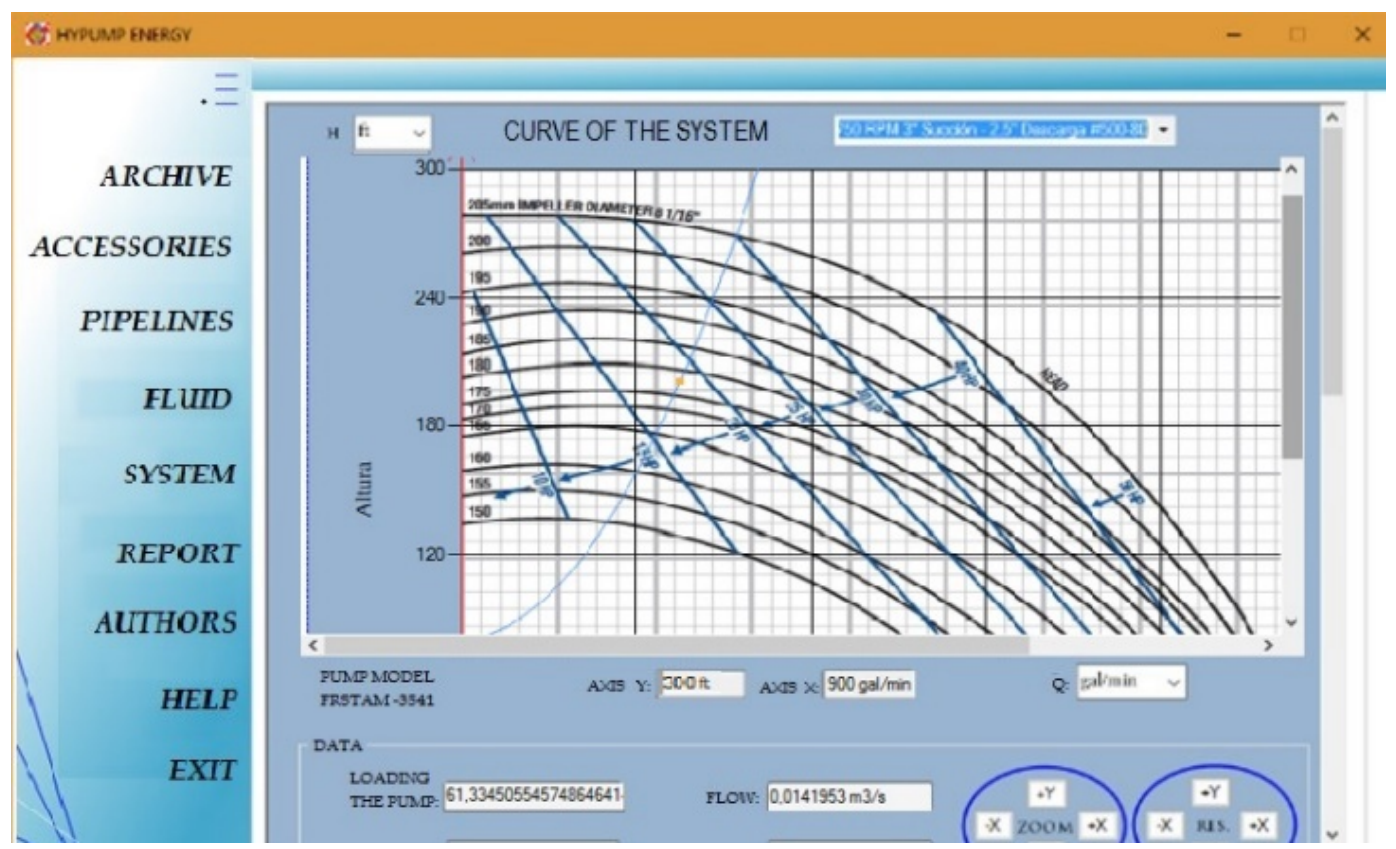

Fig. 2. Pump selected for operation, $3 "$ suction and $2.5 "$ discharge at $3500 \mathrm{rpm}$

\section{CONCLUSION}

A The energy panorama of the industrial sector requires all those involved to be more aware of the energy consumption of the systems, teams and machinery involved in the production processes in order to be more efficient and reduce to a minimum the pollution generated, due to this a new concept of active and passive energy efficiency has been developed in the last decade due to the technological advance that the monitoring devices have had in their operating systems. [17], be it Android, iOS, Windows embedded or different leading brands in HMI (Human Machine Interface) such as Siemens who have apps such as SIMATIC that allow quick access to mobile information and technology automation services to monitor the different variables with higher energy consumption and perform automated operational control.

Active energy efficiency allows, through constant monitoring, to redirect resources or modify the way they are operating in order to always obtain the best energy performance, as shown in the case study presented, The current discharge pipe is not appropriate because the diameter is smaller than the optimum, which is confirmed by the data provided by the program where a lower operating cost is generated by using the larger internal diameter pipe reducing operating costs by $55 \%$. In this case, it is recommended to change the pipe to the correct diameter and pay for this investment with the savings generated. It is clear that pumping systems are an important part of energy consumption. [18], in the industrial sector and it is necessary to monitor them so that the pumps work the longest possible time of operation as close as possible to the point of best efficiency.

\section{REFERENCES}

[1] E. Larralde and R. Ocampo, "Centrifugal pump selection process," World Pumps, vol. 2010, no. 2, pp. 24-28, 2010.

[2] E. Larralde and R. Ocampo, "Pump selection: a real example," World Pumps, vol. 2010, no. 3, pp. 28-33, 2010.

[3] J. S. Aujla, A. S. Arora, and R. Kumar, "IMPROVING ENERGY EFFICIENCY IN PUMPING SYSTEM : A CASE STUDY OF AN EDUCATIONAL INSTITUTE,” vol. 5, no. 3, pp. 717-725, 2011.

[4] D. Bravo and Y. Martínez, "Eficiencia energética, competitividad empresarial y economía verde.," Rev. Publicando, vol. 3, no. 9, pp. $447-466,2016$

[5] I. H. Bell, J. Wronski, S. Quoilin, and V. Lemort, "Pure andPseudo-pure Fluid Thermophysical Property Evaluation and the OpenSourceThermophysical Property Library CoolProp.," Ind. Eng. Chem. Res., vol. 53, no. 6, pp. 2498-2508, 2014.

[6] L. K. Reynolds, "Improving energy efficiency of pumping systems through real-time scheduling systems," Group, pp. 325-329, 2010.

[7] P. Zhou, J. Tang, J. Mou, and B. Zhu, "Effect of impeller trimming on performance," World Pumps, vol. 2016, no. 9, pp. 38-41, 2016.

[8] M. Šavar, H. Kozmar, and I. Sutlović, "Improving centrifugal pump efficiency by impeller trimming," Desalination, vol. 249, no. 2, pp. 654-659, 2009.

[9] M. Scholar and D. Meghe, “CFD Analysis of Water Flow Through Gradual Contraction Joint,” vol. 3, no. 6, pp. 1579-1581, 2014.

[10] G. Satish, K. Kumar, V. Prasad, and S. Pasha, "Comparison of Flow Analysys of a Sudden and Gradual Change of Pipe Diameter using FLUENT Software," Int. J. Res. Eng. Technol., vol. 2, no. 12, pp. 41-45, 2013.

[11] European Commission, "Study on Improving the Energy Efficiency of Pumps," no. February, 2001.

[12] F. B. Silva, A. L. Díaz, and A. M. V. Carrasco, "El triángulo de la gestión energética en la empresa: optimización de compras, mantenimiento y eficiencia energética," Ing. Ind., no. 32, pp. 11-25, 2015.

[13] K. Abdulla and S. Walke, "Simulation of Pumps by Aspen Plus," Int. J. Eng. Sci. Innov. Technol., vol. 4, no. 3, pp. 50-57, 2015.

[14] S. Iñigo, "El coste de ciclo de vida en las bombas," An. Mec. y Electr., no. Septiembre-octubre 2003, 2003.

[15] Y. Lahiouel and R. Lahiouel, "Evaluation of Energy Losses in Pipes," American Journal of Mechanical Engineering, vol. 3, no. 3A. pp. 32-37, 2015. 
[16] J. Pérez-García, E. Sanmiguel-Rojas, and A. Viedma, "New coefficient to characterize energy losses in compressible flow at Tjunctions," Appl. Math. Model., vol. 34, no. 12, pp. 4289-4305, 2010.

[17] C. David and R. Díaz, "Encuentro Internacional de Educación en Ingeniería ACOFI," in GESTIÓN Y ESTIMACIÓN DE INDICADORES DE EFICIENCIA ENERGÉTICA EN SISTEMAS DOMÉSTICOS DE ENERGÍA ELÉCTRICA SOBRE PLATAFORMA ANDROID, 2014, pp. 1-7.

[18] V. K. Arun Shankar, S. Umashankar, S. Paramasivam, and N. Hanigovszki, "A comprehensive review on energy efficiency enhancement initiatives in centrifugal pumping system,” Appl. Energy, vol. 181, no. September, pp. 495-513, 2016.

\section{AUTHOR PROFILE}

Andrs Escorcia Varela born in Barranquilla, Colombia. Is aresearch assistance in the Universidad del Atlántico. Received a degree in MechanicalEngineering from Universidad del Atlántico, located in Barranquilla, Colombia in 2016. He studied the specialization in Energy Efficient Management at Universidad del Atlántico.

Guillermo Valencia Ochoa born in Barranquilla, Colombia. Is a full-time professor at the Universidad del Atlántico. Received a degree in Mechanical Engineering from Universidad del Norte, located in Barranquilla, Colombia in 2005. Master in Mechanical Engineering from Universidad del Norte, Barranquilla, Colombia in 2008. Ph. D in Engineering from the Universidad Pontificia Bolivariana, Medellin, Colombia in 2014. He is an assistant professor of the Mechanical Engineering Program, Specialization in Energy Efficient Management and Master in Energy Management at Universidad del Atlántico.

Marley Vanegas Chamorro born in Cartagena, Colombia. Is a full-time professor at the Universidad del Atlántico. Received a degree in Chemical Engineering from Universidad del Atlántico, located in Barranquilla, Colombia in 1996. Master in Chemical Engineering from Universidad del Valle, Cali, Colombia in 1999.Ph. D inEngineering from Universidad de Oviedo,Oviedo, España in 2012. He is an associate professor of the Chemical Engineering Program, and the Master in Energy Management at Universidad del Atlántico. 